\title{
EDUCAÇÃO E DESENVOLVIMENTISMO NO PARÁ: AS POLÍTICAS "REDENTORISTAS" DO GOVERNO DE ZACARIAS DE ASSUMPÇÃO -1951 A 1956
}

\author{
Karla N. Corrêa de Almeida \\ kalmeidaufpa@gmail.com \\ Clarice Nascimento de Melo \\ mnclarice@gmail.com
}

Universidade Federal do Pará - UFPA

\section{RESUMO}

Este trabalho tem por objetivo analisar as políticas educacionais desenvolvidas no estado do Pará durante o governo de Zacarias de Assumpção nos anos compreendidos entre 1951 a 1956. Para isso buscamos compreender como as políticas de educação estadual desse período se articularam às políticas nacionais nominadas de nacional desenvolvimentistas, as quais foram articuladas na Amazônia por meio da Superintendência do Plano de Valorização Econômica da Amazônia (SPVEA). Daremos ênfase às ações locais de expansão e manutenção das instituições escolares naquele momento. Nossas fontes privilegiadas foram documentos oficiais, em especial leis relativas à educação, os quais compreendemos e tomamos na análise como documentos/monumento, na perspectiva de Le Goff. Pudemos concluir com a análise documental que a política para a educação do governo Zacarias de Assumpção se fundamentou em uma concepção redentorista e se efetivou entre a tensão das políticas modernizadoras vindas do centro para a periferia, que localmente se manifestou na contradição da (des)valorização regional, das práticas da política tradicional local e de uma diversificação de atuação no que se refere as ações de expansão e manutenção das instituições escolares.

Palavras-chave: Política Educacional; Instituições Escolares; Nacional

Desenvolvimentismo; Pará.

\section{EDUCATION AND DEVELOPMENTALISM IN PARÁ: "REDEMPTIVE" POLICIES IN THE TERM OF ZACARIAS DE ASSUMPÇÃO AS GOVERNOR - 1951 TO 1956.}

\section{ABSTRACT}

This work aims to analyze the educational policies developed in the state of Pará during the term of Zacarias de Assumpção as governor between 1951 and 1956. The research was produced in an attempt to understand how the state education policies of this period were articulated with the national policies known as national developmental, which were articulated in Amazon by Superintendence of the Economic Valorization Plan of the Amazon - SPVEA [Superintendência do Plano de Valorização Econômica da Amazônia]. Emphasis is given to local actions for expansion and maintenance of scholar institutions at that time. The main source were official documents, especially laws related to education, which were grasped and analyzed as documents/monument, from Le Goff's perspective. The conclusion made from the analysis of documents is that the educational policies during the term of Zacarias de Assumpção was based in a "redemptive" conception and was implemented between the tension of modernizing policies originated from the center to the periphery, which locally manifested itself in the contradiction of the regional (de)valuation of the local traditional policies practices and a diversification of operation regarding the actions of expansion and maintenance of school institutions.

Keywords: Educational Policy, School Institutions, National Developmentalism, Pará. 


\section{Introdução}

Este texto apresenta um primeiro resultado da pesquisa intitulada "Educação e Desenvolvimentismo no Pará: Notas da imprensa local (1950-1963)". Com este estudo pretendemos responder as seguintes questões: a quê aspectos da política nacional desenvolvimentista empreendidas no campo educacional articularam-se as políticas educacionais locais? Como se efetivaram as políticas educacionais estaduais, referentes à expansão e manutenção das instituições escolares no período de 1951 a 1956? Com essas questões pretendemos alcançar o objetivo de compreender como as políticas de educação estadual desse período se articularam às políticas nacionais nominadas de nacional desenvolvimentismo, as quais se articularam na Amazônia por meio da Superintendência de Valorização Econômica da Amazônia (SPVEA), dando ênfase às ações locais de expansão e manutenção das instituições escolares naquele momento.

A relevância deste estudo configura-se na compreensão que temos de que os estudos históricos de recorte local/regional que discutem políticas nacionais contribuem para uma melhor compreensão das particularidades de nossa história, dando ao que chamamos de história nacional as matizes concretas dessas experiências que, ao cabo, revelam partes da completude do que chamamos de nacional. Sobre isso SAVIANI (2012) nos ajuda a compreender que:

[...] não é metodologicamente apropriado encarar o local e o nacional como posições excludentes. As investigações sobre as formas específicas que a educação assume em nível local são necessárias não apenas para conhecermos essas manifestações particulares. Na verdade, são uma exigência também para o conhecimento efetivo, isto é, para a compreensão concreta da educação em âmbito nacional. Sem isso, o nacional será reduzido a mera abstração ou se tomará como nacional a manifestação local ou regional mais influente [...] (p. 27)

Portanto, a escrita de histórias locais e regionais quer inverter a tônica constante na escrita da história tradicional que traduz a história dos grandes centros urbanos como referente explicativo para todos os contextos locais. Acreditamos que a produção de conhecimento sobre experiências educativas singulares realizadas no estado do Pará, e a sua divulgação, pode cooperar para redimensionar a escrita de uma história monolítica, parcial e referenciada em ideias globalizantes. O desconhecimento das histórias locais parece ser um elemento que tem comprometido a escrita da história nacional com pluralidade. Portanto, consolidar uma historiografia educacional paraense, torna-se uma tarefa necessária, o que acreditamos estarmos contribuindo com este estudo.

Dessa forma, para efetivarmos a análise de como a chamada política nacional desenvolvimentista se materializou em âmbito local, articulando sua lógica modernizadora à educação no estado no Pará, elegemos como fontes privilegiadas documentos normativos e jornais locais.

Neste texto vamos analisar algumas Leis que se referiram as ações educacionais do Governo do Estado do Pará, no período de 1950 a 1959, mantidas no arquivo da Assembleia Legislativa do Estado do Pará (ALEPA).

Os jornais diários de circulação local foram fontes para estudo, pela sua capacidade de mostrar como a educação foi objeto de apreensão pela imprensa na relação que esta estabelecia com a sociedade em geral e com o próprio poder público e os documentos normativos, por sua vez, materializam as ações que foram efetivadas pelo Estado no seu 
papel executivo de efetivar as políticas educacionais em suas condições e contradições particulares locais.

Compreendemos o material documental no sentido que nos ensina Le Goff (1992), como documento/monumento, em contraposição a história rankeana, que busca nos documentos escritos a verdade sobre os fatos. Os encontros com os documentos se deram a partir de sua característica mais marcante: a de ser uma produção de homens e mulheres situados em locais de poder e que, portanto, sendo produto da sociedade que o fabricou e o conservou, traz consigo uma verdade parcial, situada na fala de quem o produziu e de quem o tornou um monumento, ou seja, de quem intencionalmente o marcou para constituir-se como uma marca da perpetuação de uma fala, de um sentido, de um poder. Sem esquecer a intenção mais profunda do trabalho do historiador que é compreender a temática de estudo, evitando julgamentos, para chegar às várias experiências humanas (BLOCH, 2002).

Apesar do incremento na pesquisa em história da educação da Amazônia e do Pará nos últimos anos, nota-se que em nível local, muito pouco tem se investigado sobre a educação, no período que compreende o processo de redemocratização da sociedade brasileira, ocorrido entre 1945 até o Golpe Militar de 1964.

No levantamento bibliográfico encontramos dois trabalhos significativos que tratam da educação naquele momento: o livro de Damasceno e Santos (1997) intitulado "A Educação nas Constituições paraenses: um estudo introdutório, incluindo a nova LDB" e o artigo de Rosário (2011), com o título "A influência do PCB na construção do ensino público primário de Belém do Pará, de 1945 a 1964", oriundo de sua tese de doutorado.

Na primeira obra, o objeto de estudo são as prescrições formuladas para a educação nas Constituições paraenses produzidas desde 1881 até 1989. Na segunda obra, Rosário tem como preocupação central analisar o processo de construção do ensino primário de Belém do Pará, a partir das relações existentes entre os poderes políticos instituídos e os movimentos sociais organizados liderados pelo Partido Comunista do Brasil (PCB), no período entre 1945 e 1964.

Mais recentemente foi publicado o artigo "O $1^{\circ}$ Plano Quinquenal de Valorização Econômica da Amazônia de 1955: educação para o desenvolvimento amazônico" onde Silva e Batista (2015) analisam as prescrições do âmbito da cultura e educação contidas no Programa de Desenvolvimento Cultural que integrava o Plano Quinquenal da SPVEA. Como é possível perceber, ainda existe a necessidade da ampliação de estudos que problematizem as experiências educacionais daquele período em seus movimentos e contradições sociais e políticas.

\section{A política nacional desenvolvimentista e a educação na Amazônia: entre a reconstrução nacional e a (des)valorização regional.}

A política nacional desenvolvimentista para Mota e Lopez (2015) se caracteriza pelos projetos de governos populistas, assim como pela intensificação da planificação das políticas públicas estatais, tendo como objetivo a lógica desenvolvimentista que preconizava a modernização da sociedade brasileira. Já para Marrach $(2009$, p.193) esse é o tempo do "segundo modernismo", quando emergem os movimentos sociais, movimentos culturais e no campo educacional uma forte campanha em defesa da renovação da escola pública e a defesa de uma escola moderna e científica, tendo como um de seus mais engajados articuladores, a figura de Anísio Teixeira. Para este pensador a educação seria um dos principais fatores de desenvolvimento nacional, articulada como oferta sob a responsabilidade do Estado, aberta a todos e não apenas às elites ou classes médias. Esta 
escola se sustentaria em uma formação básica comum, que capacitasse os indivíduos para o mercado de trabalho, e que revelasse talentos "elevando o nível geral de educação de todo o povo para, com esta base, erguer o corpo de especialistas e sábios que não dirigem, mas servem à massa de trabalhadores educados que governam - pelo voto - e constroem a nação" (TEIXEIRA, 1977, Apud BARREIRA, 2001).

A educação/escolarização nessa perspectiva passou a ser compreendida como fator fundamental para o desenvolvimento econômico, social e cultural da sociedade; como catalizadora da reconstrução nacional para um país moderno e desenvolvido, assentado numa sociedade urbano-industrial, com um Estado de caráter indutor dos setores de base da economia, possibilitando a integração nacional e acúmulo de capital interno mediante um novo ajuste do modelo de produção, pautado agora, no industrialismo acelerado, como se percebe na afirmação abaixo:

[...] a educação, a partir da tríade sociedade, economia e educação, ancorada pelas proposições dos planejamentos setorial e global, determinados por essa modernização da economia industrial. Assim, fazse necessário conceber o Estado brasileiro como uma complexa estrutura jurídico-política burguesa, burocrática e patrimonial, cujo viés ideológico nacionalista leva a uma vinculação estratégica do político ao administrativo, ao assumir-se como aparelho planejador, tendo como referência a necessidade de pensar a educação com os aspectos e demandas do desenvolvimentismo econômico e social. (SILVA; BATISTA, 2015)

Na Amazônia, de modo geral, e no Pará em especial, a face dessa política desenvolvimentista assentou-se em diversas medidas do governo central, sendo a mais significativa a criação da Superintendência de Valorização Econômica da Amazônia (SPVEA) em 1953, cujo objetivo era regulamentar o artigo 199, aprovado na Constituição Federal de 1946, que previa um Plano de Valorização da Amazônia.

A principal finalidade deste Plano era efetivar uma política de integração da região amazônica à dinâmica econômica do país, através de uma grande política de valorização da região, que buscava fazer com que esta superasse sua experiência extrativista avaliada então, como a causadora de todas as mazelas locais. Sobre essa questão Silva e Batista (Op. cit, p.67) nos aponta que "o ideário desenvolvimentista da SPVEA dos anos 1950 ressaltava antinomias seculares entre tradicional e moderno, progresso e o atraso [...] denotavam uma visão etnocêntrica acerca das populações Amazônicas" desmerecendo toda uma experiência social, histórica e cultural de inserção dos sujeitos naquela região.

A integração proposta se daria pela superação de diversos problemas que assolavam a Amazônia. Segundo os planejadores da SPVEA, um desses problemas era o baixo nível cultural da população, sendo que para superá-lo, uma de suas ações era o investimento na educação de base, que visava formação de agentes culturais nas comunidades locais. Outro conjunto de ações objetivava a educação escolar com ênfase na "educação profissional de todos os graus, que vulgarize, a par dos conhecimentos básicos, as técnicas de trabalho próprias da região" (SPVEA, 1954, p. 28).

Vê-se que aqui a concepção de uma educação reconstrutora propalada por Anísio Teixeira está presente de modo significativo, nas propostas da SPVEA. Não podemos aprofundar os laços dessa relação, mas de qualquer forma as ideias da educação como processo civilizatório e modernizador, circulava nos debates daquele período, daí a ênfase 
dada pelos planejadores da SPVEA na necessidade de superação do problema do "baixo nível cultural" que levava ao desconhecimento pelas populações locais, como se vê:

[...] das normas de vida e dos métodos eficientes de trabalho que a habilite a vencer os obstáculos do meio em que vivem. É impressionante a decalagem existente entre o nível de educação alcançado pelas classes superiores das grandes cidades, e o precário e primitivo nível educacional do interior. (SPVEA, 1954, p.14)

Como podemos perceber a reconstrução nacional da qual a educação era protagonista, no processo de reconstrução da região Amazônica cujo principal mote era a valorização e integração desta, na lógica de desenvolvimento nacional. Tudo isso se passava na verdade, pela desvalorização dos processos histórico-culturais das populações da região, sendo um ponto fundamental do processo desenvolvimentista na Amazônia a negação da própria região em sua lógica histórica, de convivência dos sujeitos com as florestas e rios nos processos extrativos, seus costumes e cultura. Essa negação não se deu só como suposto preconceito com as populações mais pobres, mas também a própria elite local precisou reorganiza-se na lógica dos novos ajustes produtivos, o que se configurou nas políticas de desenvolvimento da educação e das instituições escolares no estado do Pará.

\section{Notas sobre as instituições escolares paraenses entre 1950 e 1955: um olhar sobre a política "redentorista" de Zacarias de Assumpção}

O início da década de 1950 foi marcado politicamente pela disputa, entre o General Joaquim Cardoso de Magalhães Barata, que representava o Partido Social Democrático (PSD) e o General Alexandre Zacarias de Assumpção que representava a Coligação Democrática Paraense, composta pelo Partido Social Progressista (PSP), Partido Trabalhista Brasileiro (PTB), Partido Social do Trabalhador (PST), Partido Comunista do Brasil (PCdoB) e União Democrática Nacional (UDN). Um de seus motes de campanha era a redenção do estado, que já este vinha a alguns anos sendo governo pelo grupo de Barata. Este pleito foi ganho por Zacarias de Assumpção, que após uma acirrada disputa, tomou posse em 20 de fevereiro de 1951 e governou até 31 de janeiro de 1956.

No ano de 1955 Magalhães Barata retorna a disputa eleitoral, concorrendo desta vez, ao governo do estado, contra Epílogo de Campos, candidato pela Coligação Democrática Paraense (CDP), que tinha sido em 1950 o Deputado Federal paraense mais votado. A disputa de 1955 foi acirradíssima, mas desta vez a Coligação foi derrotada e Magalhães Barata, apesar a disputa judicial, tomou posse em 10 de junho de 1956, como governador eleito do Estado Pará, no entanto veio a falecer em 1959, vítima de leucemia, antes de findar seu mandato.

Esses dois governos são significativos, pois nas disputas locais, representam as duas grandes forças políticas de então: de um lado o PSD, capitaneado por Magalhães Barata e os chamados "baratistas" e a Coligação Democrática Paraense, que reunia todos aqueles que não eram "baratistas". Naquele momento não bastava apenas ser UDN, PTB, PSP ou PCdoB; era necessário ser anti Barata. Apesar de esses governos pertencerem a forças diferenciadas é neles que as políticas nacional-desenvolvimentistas para a Amazônia tomam corpo.

Interessa-nos aqui apresentar como se efetivaram as políticas educacionais estaduais referentes à expansão e manutenção das instituições escolares no período de 1950 
a 1955 no governo de Zacarias de Assumpção, onde se intensificaram as políticas referentes ao projeto de valorização da Amazônia, através da SPVEA, criada em 1953.

Logo, em 30 de agosto do mesmo ano em que assumiu o governo, Zacarias de Assumpção sancionou a Lei n. 400/51 que efetivou uma reforma administrativa substancial no governo, criando e extinguindo cargos. $\mathrm{Na}$ área educacional esta Lei, em seu artigo $2^{\circ}$, extinguiu o Departamento de Educação e Cultura, criando a Secretaria de Educação e Cultura a qual estavam subordinados a Divisão do Ensino Primário, a Divisão do Ensino Secundário e Superior, o Serviço de Educação Física e Inspetoria Escolar, o Teatro da Paz, o Museu Emílio Goeldi e a Biblioteca e Arquivo Público.

Além dessas medidas administrativas que conformam uma nova feição ao governo, vale ressaltar um aspecto interessante contido nessa Lei que é a troca dos nomes do então Educandário e da Escola de Enfermagem que se denominavam Magalhães Barata, para "Educandário Monteiro Lobato" e "Escola de Enfermagem do Pará", respectivamente. Ferrenho opositor de Magalhães Barata, Zacarias de Assumpção tomou logo a iniciativa de apagar da área educacional referências ao seu opositor.

A Secretaria de Educação e Cultura, então criada, passou a ser dirigida por José Sampaio de Campos Ribeiro, que se tornou o primeiro Secretário de Educação do Estado do Pará e que foi também o último Diretor do Departamento de Educação e Cultura. É possível afirmar que a criação de um órgão executivo próprio para a área da educação, respondeu à indicação legislativa de instituição do sistema preconizado na Constituição Estadual de 1947, assim como objetivava uma maior estruturação no que se referia às políticas de governo daquele momento. Esse movimento também é percebido por Rosário (2011) em âmbito municipal, quando esta aponta como questões significativas daquele período, além da expansão numérica das escolas, a institucionalização dos órgãos oficiais do ensino público primário municipal.

Em 1955, ainda no exercício de Zacarias de Assumpção, foi decretada a Lei $\mathrm{n}^{\circ}$ 1.191 , de 16 de julho, por onde o governo estabeleceu convênio com a SPVEA para estabelecer "cursos secundários completos ou colégios, nas cidades de Capanema, Castanhal, Abaetetuba, Altamira, Cametá, Igarapé-Açu, Marabá, Soure, Nova Timboteua, Ourém, Óbidos, e Vizeu" (art. $1^{\circ}$ ). Esses estabelecimentos deveriam atender no mínimo 200 alunos, seriam gratuitos e atenderiam a ambos os sexos. Para efetivar essa ação o Poder Executivo deveria solicitar o crédito a SPVEA, após concluir a realização de estudos para a implantação dos mesmos.

No ano anterior a essa Lei, o Pará possuía 32 (trinta e duas) unidades escolares de ensino secundário (BRASIL, Anuário de 1956, p. 346). Esse convênio significava um incremento de $40 \%$ na expansão do ensino secundário no Estado, caso fossem confirmadas as propostas presentes no decreto após os estudos a serem realizados. Percebe-se aqui que o convênio responde aos interesses expressos na perspectiva de valorização da Amazônia que afirmava que a "educação é uma atividade eminentemente social, que só pode ser praticada com êxito em grupos humanos acima de certa expressão numérica" (SPVEA, 1954, p.24). Essa perspectiva denota a concepção do planejamento como instrumento de ordenamento educacional na região.

Além das ações desenvolvidas em conjunto com a SPVEA, no governo de Assumpção, foram aprovados 26 (vinte e seis) Atos Normativos na Assembleia Legislativa do Estado do Pará, que se referiam ao que podemos compreender como expansão e desenvolvimento da educação. Foram leis referentes à construção e ampliação de prédios escolares; a conclusão de construções de prédios; a compra de prédios para funcionamento de escolas; a recuperação e reparação de prédios; ao pagamento de alugueis de prédios onde funcionavam escolas; ao equipamento de escolas além da criação de escolas. 
Foram emitidas seis Leis referentes à construção e ampliação de prédios escolares, sendo a ampliação e adaptação do prédio da Escola Técnica do Comércio do Baixo Amazonas, situada em Santarém, cujo recurso foi repassado para a Associação Comercial do baixo Amazonas, que já era responsável pela escola; a construção de um pavilhão anexo ao grupo escolar de Bragança; de um grupo escolar na "Vila de Coqueiro" em Ananindeua; de duas escolas reunidas, sendo uma em Porto Salvo em Vigia e outra na Vila de Quatipuru em Capanema. Foi também aprovada a construção do prédio de duas escolas sem caracterização, mas que acreditamos, ser escolas multisseriadas unidocentes, sendo uma em Alter do Chão, em Santarém e outra em Paricatuba em Ananindeua, que despendiam esforço financeiro do Estado, como se vê no quadro 1:

Quadro I - Construção e ampliação de prédios escolares

\begin{tabular}{|c|c|c|c|c|c|}
\hline Ano & Lei $^{\circ}$ & Ação & Tipo de escola & Local & Orçamento \\
\hline 1950 & 371 , de $26 / 08$ & $\begin{array}{l}\text { Construir } \\
\text { pavilhão anexo }\end{array}$ & Grupo escolar & Bragança & \\
\hline 1953 & 692, de $05 / 11$ & $\begin{array}{l}\text { Construção de } \\
\text { prédio }\end{array}$ & Escola Estadual & $\begin{array}{l}\text { Alter do Chão/ } \\
\text { Santarém }\end{array}$ & \\
\hline 1954 & 924 , de $25 / 12$ & $\begin{array}{l}\text { Construção de } \\
\text { edifício }\end{array}$ & $\begin{array}{l}\text { Escolas } \\
\text { Reunidas }\end{array}$ & Porto Salvo/ Vigia & $150.000,00$ \\
\hline 1954 & 949 , de $31 / 12$ & $\begin{array}{l}\text { Construção de } \\
\text { prédio }\end{array}$ & $\begin{array}{l}\text { Escolas } \\
\text { Reunidas }\end{array}$ & $\begin{array}{l}\text { Vila de } \\
\text { Quatipuru/Capane } \\
\text { ma }\end{array}$ & $250.000,00$ \\
\hline 1955 & 968 , de $21 / 01$ & $\begin{array}{l}\text { Construção de } \\
\text { Prédio }\end{array}$ & Escola & $\begin{array}{l}\text { Paricatuba/ } \\
\text { Ananindeua }\end{array}$ & $50.000,00$ \\
\hline 1955 & 1.151, de $20 / 05$ & $\begin{array}{l}\text { Construção de } \\
\text { prédio }\end{array}$ & Grupo Escolar & $\begin{array}{l}\text { Vila de Coqueiro/ } \\
\text { Ananindeua }\end{array}$ & $100.000,00$ \\
\hline 1955 & 1.166 , de $27 / 06$ & $\begin{array}{l}\text { Ampliação e } \\
\text { adaptação do } \\
\text { prédio }\end{array}$ & $\begin{array}{l}\text { Escola Técnica } \\
\text { do Comércio do } \\
\text { Baixo } \\
\text { Amazonas }\end{array}$ & Santarém & $150.000,00$ \\
\hline
\end{tabular}

Fonte: Elaborado pelas autoras.

Não podemos afirmar que essas construções de prédios, significassem efetivamente ampliação da oferta de ensino, pois era muito comum nesse período, que particulares ou até mesmo partidos políticos através de suas lideranças locais, pagassem professores para assumirem turmas, em especial nas escolas multisseriadas; depois essas "escolas" já instaladas, entravam numa pauta de negociações com o governo, de modo que fossem incorporadas ao aparelho estatal. Esses casos eram inclusive, noticiados na imprensa paraense:

Mantida pela União Democrática Nacional, inaugurou-se a 19 de abril passado, no Alto Pererú, município de São Caetano de Odivelas, a escola primária "Coronel João Rodrigues dos Santos". Presidiu o ato o sr. Epaminondas de Souza Chagas, representando o capitão Inácio de Oliveira Santos, que, em nome da população escolar do Alto Pererú, agradace à União Democrática Nacional a criação e custeio da escola. Em seguida, fez-se a matrícula de quarenta e duas crianças, sob estrondosas palmas [...] Está de parabéns, pois, o presidente do Diretório Municipal da UDN, em São Caetano de Odivelas, sr. Miguel Arcanjo Ferreira Filho. Dezenas de criancinhas de seu torrão natal vão receber instrução na 
escola que o seu grande partido criou no povoado do Alto Pererú. (FOLHA DO NORTE, 1950, p. 8)

Como se vê, uma Lei autorizando a construção de um prédio escolar, não significava necessariamente a expansão da oferta de ensino, mas apenas o ajuste legal, para responder inclusive às demandas já atendidas por esforços da própria sociedade civil, mas que ainda precisavam ser assumidas pelo poder público.

A educação, através principalmente da instrução primária, se configurava em uma das moedas de troca política mais significativa, num estado marcado pelas distâncias físicas, dificuldades de transporte e até mesmo pela ausência do poder público.

Outro aspecto significativo que surgiu do estudo sobre essas Leis aprovadas educação no governo de Zacarias de Assumpção, foi a quantidade de créditos aprovados para pagamento de aluguel de prédios onde funcionavam escolas públicas estaduais. A princípio esse aspecto poderia não seria significativo, pois se o poder público aluga um prédio, tem por obrigação pagá-lo. Contudo, a dinâmica que se apresentam nos Decretos nos remete a indícios que podem denotar práticas de troca de favores políticos.

Uma análise atenta dos créditos liberados para esse fim nos indica que os anos de 1954, 1955 e 1956 foram os anos do governo onde aparece a disponibilização desses recursos. Foram ao todo nesses três anos, aprovados um montante de Cr\$ 57.225,00 (Cinquenta e sete mil, duzentos e vinte e cinco cruzeiros) que foram pagos a 140 proprietários de prédios alugados para funcionamento de escolas, esses pagamentos variavam de 150 a 1.800 cruzeiros. Vale ressaltar que os períodos aos quais tais pagamentos referiam-se, variavam entre os anos de 1946 a 1952.

Zacarias de Assumpção ainda pagou dívidas de seu antecessor e concentrou pagamentos de seu próprio governo, para o ano de 1955 quando ocorreriam novas eleições. Mais uma vez, percebe-se uma prática populista e maniqueísta que faz da educação moeda de troca política. No ano de 1956, logo depois de deixar o governo, a Assembleia Legislativa, aprovou uma lei que liberava o pagamento de 12.260 cruzeiros para o pagamento de 43 proprietários de prédios que foram utilizados como escola estadual no exercício de 1951 a 1952, ou seja, ainda de mandato anterior ao de Assumpção.

No governo de Assumpção também foram aprovadas entre 1953 e 1955 a instalação e criação de escolas. A Lei $n^{\circ} 815$, de 17 de setembro de 1954 preconizava a instalação e funcionamento da Escola Normal de Breves, com um orçamento de 40 mil cruzeiros. Vêse aqui o processo de expansão do ensino normal para cidades que aglutinavam regiões do próprio estado. A Lei no 926, de 15 de dezembro de 1954 previa a instalação da "Escola Técnica Industrial de Bragança" devendo ser instalada, aproveitando a Granja Taíra, que era de propriedade do município. O curso previsto para Bragança era a formação de sapateiro e marceneiro.

Em 1953 foi criada uma escola isolada na localidade de Santo Antônio, no distrito de Cuinarana em Marapanin (Lei no 752, de 28 de dezembro); em 1955 foi criada a "Escola Agro artesanal em Marapanim" que teve seu orçamento de manutenção garantido pela SPVEA, pois o ensino agrícola era um dos grandes investimentos da proposta de valorização da Amazônia. Vemos aqui mais uma vez a esfera estadual articular-se ao Plano de valorização nacional para a região. Sobre isso Marques (2013) aponta-nos que uma das contradições da SPVEA foi a concentração de recursos financeiros no estado do Pará, o que resultou em poucas reclamações por ocasião de sua extinção na década de 1960. Nesse movimento, em 1955 também foram criadas cinco escolas primárias três no interior, nas localidades de Monteiro, Bussú e Retiro em Curuçá e duas em Belém nos "subúrbios" da Marambaia e do Umarizal, como está no quadro 2. 
Quadro 2: Criação de Escolas

\begin{tabular}{|l|l|l|l|l|c|}
\hline Ano & Lei n & Ação & Tipo de escola & Local & Orçamento \\
\hline 1953 & $\begin{array}{l}752, \text { de } \\
28 / 12\end{array}$ & $\begin{array}{l}\text { Criação de } \\
\text { escola }\end{array}$ & $\begin{array}{l}\text { Escola Isolada de } 1^{\text {a }} \text { Classe } \\
\text { padrão B }\end{array}$ & $\begin{array}{l}\text { Povoação Sto } \\
\text { Antônio de } \\
\text { Distrito de } \\
\text { Cuinarana/ } \\
\text { Marapanim }\end{array}$ & \\
\hline 1955 & $\begin{array}{l}1.155, \text { de } \\
23 / 05\end{array}$ & $\begin{array}{l}\text { Criação de } \\
\text { Escola }\end{array}$ & Escola Agro artesanal & Marapanim & $333.900,00$ \\
\hline 1955 & 1.153, de & $\begin{array}{l}\text { Criação de } \\
\text { escolas }\end{array}$ & $\begin{array}{l}5 \text { escolas primárias padrão } \\
\text { A }\end{array}$ & $\begin{array}{l}\text { Monteiro, Bussú, } \\
\text { Retiro/Curuçá e } \\
\text { subúrbios da } \\
\text { cidade } \\
\text { Marambaia e } \\
\text { Umarizal }\end{array}$ & \\
\hline
\end{tabular}

Fonte: Quadro elaborado pelas autoras.

Esse quadro nos dá uma melhor visibilidade da contradição entre o projeto que pretende desenvolver a Amazônia com os caminhos da educação e a pequena quantidade de criação de escolas. Em três anos apenas sete escolas de diferentes tipos.

Não podemos deixar de registrar também que em 1953 foi aprovado um crédito de um milhão de cruzeiros para "equipar com carteiras, mesas e quadros negros" as escolas públicas do interior do Estado. Para definir como esse material seria distribuído a Lei $\mathrm{n}^{\circ}$ 628, de 10 de agosto determinava que o poder executivo deveria apresentar a Assembleia Legislativa um plano para distribuição do material. Nota-se aqui a preocupação do poder legislativo em inferir sobre o processo em suas regiões, talvez em ligação direta com suas bases eleitorais.

A recuperação de prédios também foi desenvolvida no Governo de Assumpção. Foram recuperados 4 grupos escolares entre 1953 e 1955. Estes ficavam localizados em Abaetetuba, Ponta de Pedras, Primavera/Capanema e Breves. Parece que as ações de construção, ampliação, instalação e criação de escolas privilegiaram as escolas primárias, as escolas secundárias e técnicas profissionalizante e a recuperação de prédios ficou para os grupos escolares.

Uma análise do governo de Zacarias de Assumpção nos sugere que sua política de expansão e manutenção das instituições escolares no Estado do Pará deu-se de forma diversificada, atendendo desde a construção e criação de prédios e escolas até o equipamento básico das mesmas. Percebe-se que foram desenvolvidas ações para a escola primária, para o ensino secundário técnico e profissionalizante, respondendo as propostas de valorização e integração da região as políticas econômicas e educacionais do período em que a educação é colocada como redentora da sociedade nacional e amazônica, pois lhe caberia civilizar e formar de um novo sujeito o sujeito urbano, consumidor e trabalhador numa indústria cada vez mais diversificada em nosso país e região.

Mas suas políticas "redentoristas" encontraram limites evidenciados pela tensão entre as demandas efetivamente locais e as políticas modernizadoras vindas do centro para a periferia, o nacional desenvolvimentismo, que localmente se manifesta na contradição entre a (des) valorização regional e o projeto de educação civilizatória e modernizante. Por outro lado as práticas do governo cambiavam ainda por entre relações populistas e 
clientelísticas principalmente no que se referia a instrução primária, que continuava sendo privilegiada como moeda política nas ações de expansão e manutenção das instituições escolares, numa realidade que se encontrava longe de um padrão democraticamente aceitável, até mesmo para os mais liberais e que reproduzia a lógica de um movimento de expansão da educação escolar de forma desigual e combinada, cem sua forma específica, mas em sintonia do projeto desenvolvimentista nacional.

\section{Referências}

BARREIRA. Luiz Carlos. Anísio Teixeira e a Doutrina do NacionalDesenvolvimentismo. Quaestio - Revista de Estudos de Educação, Ano 03, n. 1, maio de 2001.

BLOCH, Marc. A apologia da história. Ou o ofício do historiador. Tradução André Teles. Rio de Janeiro: Jorge Zahar Ed., 2001.

BRASIL. Anuário Estatístico do Brasil - 1955, Ano XVI.

DAMASCENO, Raimundo Alberto; SANTOS, Émina Márcia. A educação nas Constituições paraenses: um estudo introdutório, incluindo a nova LDB. Belém: Gráfica e Editora da Universitária, UFPA, 1997.

LE GOFF, Jacques. História e memória. Campinas: Editora da UNICAMP, 1992.

MARACH, Sonia. Outras histórias da educação: do iluminismo à indústria cultural (1823-2005). São Paulo: Ed. UNESP, 2009.

MARQUES, Gilberto S. SPVEA: o Estado na crise do desenvolvimento regional amazônico (1953-1966) Disponível em: http://revista.sep.org.br/index.php/SEP/article/view/6 HYPERLINK "http://revista.sep.org.br/index.php/SEP/article/view/6. Acesso em 05.02.2015". Acesso em: 5 de fevereiro de 2015.

PARÁ. Lei no 400, de 30 de agosto de 1951. Cria cinco Secretarias de Estado, estabelece subordinação de órgãos administrativos, extingue cargos e órgãos administrativos e dá outras providências. In: Diário Oficial do Estado do Pará, no ${ }^{\circ} 16.817$, de 6 de setembro de 1961.

PARÁ. Lei no 628, de 10 de agosto de 1953. Autoriza o Poder Executivo a aplicar no decorrer do ano de 1954, a importância de um milhão de cruzeiros, destinado a equipar com carteiras, mesas e quadros-negros as escolas públicas do interior do estado. In: Diário Oficial do Estado do Pará, no 17.398, de 23 de agosto de 1953.

PARÁ. Lei no 752, de 28 de dezembro de 1953. Cria a Escola Isolada de $1^{\text {a }}$ classe, padrão B, na povoação Santo Antonio, distrito de Cuinarana, Município de Marapanim. In: Diário Oficial do Estado do Pará, nº 17.502, de 20 de dezembro de 1953.

PARÁ. Lei no 815, de 17 de setembro de 1954. Autoriza o Poder Executivo a abrir crédito especial para a instalação e funcionamento da Escola Normal Regional de Breves. In: Diário Oficial do Estado do Pará, no 17.721, de 25 de setembro de 1954.

PARÁ. Lei no 926, de 12 de dezembro de 1954. Autoriza o Govêrno do Estado a assinar um convênio com o Município de Bragança para instalar nesse Município uma escola 
Técnica Industrial. In: Diário Oficial do Estado do Pará, no 17.795 , de 25 de dezembro de 1954.

PARÁ. Lei no 1.191, de 16 de julho de 1955. Autoriza o Govêrno do Estado a promover Convênio com a Valorização Econômica da Amazônia, tendente à instituição de Colégios Secundários nas diversas cidades do interior do Estado. In: Diário Oficial do Estado do Pará, no 17.961, de 23 de julho de 1955.

ROSÁRIO, Maria José Aviz do. A influência do PCB na construção do ensino público primário de Belém do Pará, de 1945 a 1964. Revista HISTEDBR On-line, Campinas, número especial, out.2011. (p. 42-60)

SAVIANI, Demerval. O local e o nacional na historiografia da educação brasileira. In: ROSÁRIO, Maria José; MELO, Clarice Nascimento; LOMBARDI, (orgs.). O nacional e o local na história da educação. Campinas: Alínea, 2012. (p.15-30)

SILVA. José Bittencourt; BATISTA, Iane Maria da Silva. $1^{\circ}$ Plano Quinquenal de Valorização Econômica da Amazônia de 1955: educação para o desenvolvimento amazônico. In: Revista HISTEDBR On-Line, Campinas, nº 66, dez. 2015. (p.56-72)

PARÁ. Superintendência do Plano de Valorização Econômica da Amazônia (SPVEA). Concepção Preliminar da Valorização Econômica da Amazônia. Belém: Setor de Coordenação, 1954.

Folha do Norte. União Democrática Nacional. Belém, 4 de maio de1950, p.8.

Recebido: novembro/16 Aprovado: dezembro/16 